\title{
Long-Term Outcome of Neoadjuvant Endocrine Therapy with Aromatase Inhibitors in Elderly Women with Hormone Receptor- Positive Breast Cancer
}

\author{
Antonino Grassadonia, $\mathrm{MD}^{1}$, Marta Di Nicola, $\mathrm{PhD}^{2}$, Simona Grossi, $\mathrm{MD}^{3}$, Paolo Noccioli, $\mathrm{MD}^{3}$, Saveria Tavoletta, \\ $\mathrm{MD}^{3}$, Roberto Politi, $\mathrm{MD}^{3}$, Domenico Angelucci, $\mathrm{MD}^{4}$, Camilla Marinelli, $\mathrm{MD}^{4}$, Marinella Zilli, $\mathrm{MD}^{5}$, \\ Giampiero Ausili Cefaro, $\mathrm{MD}^{6}$, Nicola Tinari, $\mathrm{MD}^{1}$, Michele De Tursi, $\mathrm{MD}^{\mathbf{1}}$, Laura Iezzi, $\mathrm{MD}^{5}$, Pasquale Cioffi, \\ $\mathrm{MD}^{7}$, Stefano Iacobelli, $\mathrm{MD}^{1}$, Clara Natoli, $\mathrm{MD}^{1}$, and Ettore Cianchetti, $\mathrm{MD}^{8}$ \\ ${ }^{1}$ Medical Oncology Unit, Department of Experimental and Clinical Sciences, University 'G. d'Annunzio', Chieti, Italy; \\ ${ }^{2}$ Laboratory of Biostatistics, Department of Experimental and Clinical Science, University 'G. d'Annunzio', Chieti, Italy; \\ ${ }^{3}$ Division of Surgical Senology, 'G. Bernabeo' Hospital, Ortona, CH, Italy; ${ }^{4}$ Division of Pathology, 'SS. Annunziata' \\ Hospital, Chieti, Italy; ${ }^{5}$ Oncology Department, 'SS. Annunziata' Hospital, Chieti, Italy; ${ }^{6}$ Radiation Oncology Department, \\ University 'G. d'Annunzio', Chieti, Italy; ${ }^{7}$ Hospital Pharmacy, 'SS. Annunziata' Hospital, Chieti, Italy; ${ }^{8}$ Division of \\ Surgical Senology, Department of Experimental and Clinical Sciences, University 'G. d'Annunzio', Chieti, Italy
}

\begin{abstract}
Background. Aromatase inhibitors (AIs) are more effective than tamoxifen as neoadjuvant endocrine therapy (NET) for hormone receptor (HR)-positive breast cancer. Here we report the surgical and long-term outcome of elderly postmenopausal patients with locally advanced, HR-positive breast cancer treated with preoperative AIs.

Methods. Between January 2003 and December 2012, 144 postmenopausal patients inoperable with breast conservative surgery (BCS) received letrozole, anastrozole, or exemestane as NET. Patients underwent breast surgery and received adjuvant AIs. Adjuvant systemic therapy, chemotherapy and/or trastuzumab, and adjuvant radiotherapy were administered as appropriate, but limited to high-risk patients with few or no comorbidities.
\end{abstract}

Results. After a median follow-up of 49 months, 4 (3.0\%) patients had local relapse, 18 (12.5\%) had distant metastases, and $24(17.0 \%)$ died. BCS was performed in $121(84.0 \%)$ patients. A tumor size $<3 \mathrm{~cm}$ and human epidermal growth factor receptor 2 (HER2) negativity were predictors of BCS. The achievement of BCS and grade G1 were significantly associated with longer disease-free

(C) The Author(s) 2014. This article is published with open access at Springerlink.com

First Received: 19 September 2013;

Published Online: 13 February 2014

C. Natoli, MD

e-mail: natoli@unich.it survival (DFS) ( $p=0.009$ and $p=0.01$, respectively) and overall survival ( $p=0.002$ and $p=0.005$, respectively). Residual tumor $\leq 2 \mathrm{~cm}$ (yT0-yT1) in the longest diameter after NET was also statistically associated with longer DFS $(p=0.005)$.

Conclusions. The results of this retrospective study indicate that elderly breast cancer patients with a tumor size $<3 \mathrm{~cm}$ at diagnosis and HER2 negativity have a higher probability of achieving BCS after NET. Moreover, patients treated with BCS and with grade G1 tumor have a reduced risk of recurrence and death in the long-term follow-up.

Neoadjuvant endocrine therapy (NET) has been historically administered to patients with locally advanced breast cancer and unfit for chemotherapy because of age and/or comorbidities. $^{1,2}$ New perspectives on the use of NET in healthy postmenopausal women have recently emerged on the basis of studies showing that patients with hormone receptor (HR)-positive breast cancer hardly achieve pathologic complete response (pCR) after neoadjuvant chemotherapy, thus suggesting that HR-positive tumors are quite resistant to this therapeutic approach. ${ }^{3-10}$ Moreover, patients who do not achieve a pCR to neoadjuvant chemotherapy maintain a good prognosis even in the presence of residual disease. ${ }^{11,12}$ The good outcome of these patients is largely dependent on the efficacy of postoperative endocrine therapy, especially when based on the third- 
generation aromatase inhibitors (AIs) letrozole, anastrozole, and exemestane. In postmenopausal women, adjuvant AIs have been shown to be superior to tamoxifen in terms of disease-free survival (DFS) and overall survival (OS). ${ }^{13-15}$ Similarly, in the neoadjuvant treatment of postmenopausal women with breast cancer, AIs allow higher rates of objective responses and breast conservative surgery (BCS) to be achieved than tamoxifen. ${ }^{16-19}$

Few studies have assessed the impact of response to neoadjuvant $\mathrm{AI}$ on the $\mathrm{OS}$ of patients with HR-positive breast cancer. This study was conducted to evaluate the long-term outcome of elderly postmenopausal women with locally advanced HR-positive breast cancer treated with neoadjuvant AIs in our institution.

\section{PATIENTS AND METHODS}

\section{Patients}

The study population was identified by a systematic review of the chart of all women with locally advanced breast cancer, candidates to mastectomy, and consecutively treated with NET - letrozole, anastrozole, or exemestanebetween January 2003 and December 2012. All patients had a diagnosis of HR-positive invasive breast cancer as established by tru-cut biopsy of the primary tumor and immunohistochemistry (IHC), and were postmenopausal. The study has been approved by our institutional Ethics Committee.

\section{Treatments}

Mastectomy or BCS were performed after NET as indicated by the surgeon. Axillary lymph node dissection or sentinel node biopsy were performed according to surgeon judgment. After surgery, AIs were continued as adjuvant treatment in all patients. Adjuvant chemotherapy was administered to high-risk, non-responsive patients with few or no comorbidities. Adjuvant trastuzumab was also considered for patients with human epidermal growth factor receptor 2 (HER2)-positive tumor. Adjuvant breast radiotherapy was delivered to patients who underwent BCS and to patients treated with mastectomy and stage cT3, cN2 or $\mathrm{cN} 3$ at diagnosis or stage $\mathrm{pN} 2$ after surgery. However, in patients unfit for age or comorbidities, radiotherapy was not administered. ${ }^{20}$

\section{Clinical Evaluation}

The clinical response to NET was evaluated by measuring the largest diameter of the tumor by caliper at baseline, every month and just before surgery. Mammography and breast ultrasound were also performed, but data were not available for all patients. The Response Evaluation Criteria in Solid Tumors (RECIST) were utilized to define clinical responses: complete response (CR), partial response (PR), stable disease (SD), and progressive disease (PD). ${ }^{21}$

\section{Pathological Assessment}

Tru-cut biopsies and surgical specimens were both processed to determine morphological and molecular features. Histological type and grade of carcinoma were assessed on hematoxylin and eosin-stained tumor sections. The tumor grade was scored according to the Elston-Ellis classification. The expression of estrogen (ER), progesterone receptors (PR), HER2, and Ki-67 were evaluated by IHC. Cut-off positivity for HR was fixed at $10 \%$ of tumor cells stained for ER and/or PR. ${ }^{22}$ HER2 status was assessed by HercepTest (Dako Italia, Milan, Italy). Tumors with a score of $3+$ by IHC, or gene amplification by fluorescence or chromogenic in situ hybridization (FISH or CISH), were considered as HER2 positive. IHC detection of Ki-67 was performed using the MIB-1 antibody.

pCR was defined as the absence of invasive cancer within the breast (ypT0/is) and lymph node (ypN0), after extensive sampling, i.e. at least ten sections, $2-4 \mu \mathrm{m}$ in thickness, from three different regions of the initial tumor site, as proposed by Kuerer et al. ${ }^{12}$ Pathological stages were categorized according to the American Joint Committee on Cancer Staging Manual, 7th edition.

\section{Statistical Analysis}

Logistic regression was applied to identify variables predictive of BCS. The results of the model were expressed as odds ratio (OR) and relative $95 \%$ confidence interval (CI). Multivariate logistic regression was applied to evaluate the adjusted ORs. The Kaplan-Meier method was used to calculate the 5-year rates of DFS and OS. OS was defined as the time between surgery and death or last follow-up visit, and DFS as the time between surgery and the first verified event. Differences between curves were evaluated by the log-rank test. To identify independent prognostic factors with significant impact on DFS and OS, multivariate analyses were performed using the Cox proportional hazards model. Calculating the exponential of the regression coefficients from the Cox model provided an estimate of the hazard ratio (HR) and the $95 \%$ CI. Stability of models was guaranteed by backward fitting procedure. A $p$ value of 0.05 or less was considered statistically significant. All statistical analysis was performed using SPSS ${ }^{\circledR}$ software 11.0 (SPSS Inc, Chicago, IL, USA). 
TABLE 1 Pre-treatment clinical characteristics of patients

\begin{tabular}{ll}
\hline Variable & \\
\hline Mean age at surgery, years (mean \pm SD) & $76.4 \pm 8.2$ \\
Age at surgery (years) $[n(\%)]$ & $14(9.7)$ \\
$\leq 65$ & $131(90.3)$ \\
$>65$ & \\
Clinical T (cm) $[n(\%)]$ & $66(45.8)$ \\
$\leq 3$ & $78(54.2)$ \\
$>3$ & \\
Histologic type $[n(\%)]$ & $137(95.1)$ \\
Ductal & $5(3.5)$ \\
Lobular & $2(1.4)$ \\
Others & \\
Tumor grade $[n(\%)]$ & $95(66.0)$ \\
G1 & $38(26.4)$ \\
G2 & $4(2.8)$ \\
G3 & $7(4.8)$ \\
Unknown & \\
Molecular subtype $[n(\%)]$ & $131(91.0)$ \\
HER-2 negative & $13(9.0)$ \\
HER-2 positive & \\
Ki-67 $(\%)[n(\%)]$ & $88(61.1)$ \\
$\leq 14$ & $40(27.8)$ \\
$>14$ & $16(11.1)$ \\
Unknown & $5.7 \pm 1.5$ \\
Duration of NET, months (mean \pm SD) & \\
\hline
\end{tabular}

$B C S$ breast conservative surgery, $N E T$ neoadjuvant endocrine therapy, $H E R-2$ human epidermal growth factor receptor 2

\section{RESULTS}

\section{Patient and Tumor Characteristics at Baseline}

Overall, 144 patients were identified and included in the study. All patients were treated with third-generation AIs: 56 (38.9\%) patients received letrozole, 83 (57.6\%) exemestane, and $5(3.5 \%)$ anastrozole. Patients' characteristics are illustrated in Table 1. Mean age was 76.4 years $( \pm 8.2$ years $)$, with $131(90.3 \%)$ patients being older than 65 years. More than half of the study population had a tumor size $>3 \mathrm{~cm}$ in the largest diameter, and the most frequent cancer histotype was invasive ductal carcinoma. Tumor grade was $\mathrm{G} 1$ in $95(66 \%)$ patients, and Ki-67 was $\leq 14 \%$ in $88(61.1 \%)$ patients. Only $13(9.0 \%)$ patients had HER2-positive tumor. The mean duration of NET was 5.7 months ( \pm 1.5 months).

\section{Clinical Response and Surgery Outcome}

Of 135 patients evaluable for clinical response, CR was obtained in 13 (9.6\%), PR in $104(77.0 \%)$, SD in 16 $(11.8 \%)$, and PD in $2(1.5 \%)$. The type of hormonal agent used did not significantly influence clinical response (data not shown). With the exception of four patients with PR who required mastectomy, all patients reporting objective response $(\mathrm{CR}+\mathrm{PR})$ received $\mathrm{BCS}$. Axillary lymph node dissection was performed in $97(67.4 \%)$ patients, including nine with nodal involvement at sentinel node biopsy at surgery.
TABLE 2 Univariate and multivariate analysis of variables predictive of $\mathrm{BCS}$ surgery

Bold values indicate significant $p$ values

'Unknown' were not included in the analysis

$B C S$ breast conservative surgery, $N E T$ neoadjuvant endocrine therapy, $C I$ confidence interval, HER-2 human epidermal growth factor receptor 2

\begin{tabular}{|c|c|c|c|c|}
\hline \multirow[t]{2}{*}{ Variable } & \multicolumn{2}{|l|}{ Univariate } & \multicolumn{2}{|l|}{ Multivariate } \\
\hline & Odds ratio $(95 \% \mathrm{CI})$ & $p$ Value & Odds ratio $(95 \% \mathrm{CI})$ & $p$ Value \\
\hline \multicolumn{5}{|c|}{ Age at surgery (years) } \\
\hline$>65$ & 1.00 & & 1.00 & \\
\hline$\leq 65$ & $2.42(0.30-19.59)$ & 0.407 & $2.92(0.27-21.37)$ & 0.376 \\
\hline \multicolumn{5}{|l|}{ Clinical T (cm) } \\
\hline$>3$ & 1.00 & & 1.00 & \\
\hline$\leq 3$ & $2.79(1.03-7.55)$ & 0.044 & $5.48(1.35-20.20)$ & 0.017 \\
\hline \multicolumn{5}{|l|}{ Molecular subtype } \\
\hline HER-2 positive & 1.00 & & 1.00 & \\
\hline HER-2 negative & $5.75(1.72-19.15)$ & 0.004 & $4.93(1.09-19.85)$ & 0.050 \\
\hline \multicolumn{5}{|l|}{ Grade } \\
\hline G2-G3 & 1.00 & & 1.00 & \\
\hline G1 & $3.01(1.17-7.80)$ & 0.023 & $2.35(0.68-8.12)$ & 0.175 \\
\hline \multicolumn{5}{|l|}{ Ki-67 (\%) } \\
\hline$>14$ & 1.00 & & 1.00 & \\
\hline$\leq 14$ & $2.03(0.77-5.39)$ & 0.154 & $2.37(0.54-10.27)$ & 0.250 \\
\hline Duration of NET & $1.05(0.77-1.43)$ & 0.753 & $0.99(0.66-1.50)$ & 0.942 \\
\hline
\end{tabular}


After NET, BCS was performed in $121(84 \%)$ patients and mastectomy in $23(16 \%)$ patients. The probability of achieving BCS according to the clinicopathologic characteristics of patients is shown in Table 2. At univariate analyses, factors predictive for $\mathrm{BCS}$ were $\mathrm{cT} \leq 3 \mathrm{~cm}(p=0.031)$, HER-2 negativity ( $p=0.002)$, and grade G1 $(p=0.02)$. At multivariate analyses, only a small tumor size, i.e. cT $\leq 3 \mathrm{~cm}$ at diagnosis ( $p=0.017)$ and HER-2 negativity $(p=0.05)$ remained significant predictors of BCS.

\section{Pathological Response and Adjuvant Therapy}

A pCR (ypT0/is; ypN0) was obtained in only two patients, and absence of cancer in the breast but not in the nodes (ypT0/ is; ypN1) in three patients. After surgery, adjuvant treatment with AIs was continued in all patients, but in 22 patients it was preceded by adjuvant chemotherapy. A total of $125(87 \%)$ patients maintained the same AI in the adjuvant setting. Patients with non-responsive tumor were switched to another non-cross-resistant agent: $14(10 \%)$ from letrozole to exemestane, and 5 (3\%) from exemestane to letrozole. Of 13 patients with HER2-positive tumors, 7 received trastuzumab, in 4 cases in combination with chemotherapy.

Adjuvant radiotherapy was delivered to 77 (64\%) of 121 patients who underwent BCS, and to 5 (22\%) of 23 patients who underwent mastectomy. Radiotherapy was not delivered to 44 (36\%) patients with BCS and to $9(64 \%)$ of 14 patients with mastectomy.
TABLE 3 Univariate analysis of factors predictive of 5-year disease-free survival and overall survival
Bold values indicate significant $p$ values

$H R$ hazard ratio, $C I$ confidence interval, HER-2 human epidermal growth factor receptor $2, B C S$ breast conservative surgery, $R T$ radiotherapy

${ }^{a}$ Unadjusted Kaplan-Meier estimates

\begin{tabular}{|c|c|c|c|c|c|c|c|}
\hline \multirow[t]{2}{*}{ Variable } & \multirow[t]{2}{*}{$n$} & \multicolumn{3}{|c|}{ Disease-free survival } & \multicolumn{3}{|c|}{ Overall survival } \\
\hline & & $\begin{array}{l}5 \text {-year } \\
(\%)^{\mathrm{a}}\end{array}$ & $\operatorname{HR}(95 \% \mathrm{CI})$ & $p$ Value & $\begin{array}{l}5 \text {-year } \\
(\%)^{\mathrm{a}}\end{array}$ & $\mathrm{HR}(95 \% \mathrm{CI})$ & $p$ Value \\
\hline \multicolumn{8}{|c|}{ Age at surgery (years) } \\
\hline$\leq 65$ & 14 & 83.1 & 1.00 & & 92.3 & 1.00 & \\
\hline$>65$ & 131 & 83.5 & $1.02(0.24-4.37)$ & 0.981 & 81.7 & $1.12(0.26-4.82)$ & 0.882 \\
\hline \multicolumn{8}{|l|}{ Molecular subtype } \\
\hline HER-2 negative & 131 & 86.4 & 1.00 & & 83.7 & 1.00 & \\
\hline HER-2 positive & 13 & 47.5 & $3.93(1.44-10.75)$ & 0.008 & 70.3 & $1.92(0.65-5.64)$ & 0.235 \\
\hline \multicolumn{8}{|l|}{ Grade (basal) } \\
\hline G1 & 95 & 94.3 & 1.00 & & 91.8 & 1.00 & \\
\hline G2-G3 & 42 & 57.3 & 8.57 (3.14-23.42) & $<\mathbf{0 . 0 0 1}$ & 62.6 & $4.35(1.84-10.27)$ & 0.001 \\
\hline \multicolumn{8}{|l|}{ Type of surgery } \\
\hline BCS & 121 & 88.6 & 1.00 & & 86.1 & 1.00 & \\
\hline Mastectomy & 23 & 57.5 & $4.46(1.88-10.59)$ & 0.001 & 65.8 & $4.15(1.85-9.29)$ & 0.001 \\
\hline \multicolumn{8}{|l|}{ Ki67 (basal; \%) } \\
\hline$\leq 14$ & 88 & 88.9 & 1.00 & & 81.7 & 1.00 & \\
\hline$>14$ & 40 & 64.6 & $4.09(1.67-10.04)$ & 0.002 & 76.1 & $1.53(0.66-3.55)$ & 0.317 \\
\hline \multicolumn{8}{|c|}{$\mathrm{T}$ stage (after surgery) } \\
\hline yT0-yT1 & 66 & 94.5 & 1.00 & & 85.6 & 1.00 & \\
\hline yT2-yT3 & 78 & 74.5 & $5.42(1.60-18.41)$ & 0.007 & 79.7 & $2.36(0.94-5.95)$ & 0.069 \\
\hline \multicolumn{8}{|c|}{ No. of metastatic nodes } \\
\hline None & 85 & 91.1 & 1.00 & & 83.6 & 1.00 & \\
\hline$\leq 3$ & 34 & 86.7 & $1.34(0.39-4.58)$ & 0.640 & 88.1 & $1.48(0.13-1.81)$ & 0.259 \\
\hline$>3$ & 25 & 55.9 & $5.56(2.12-11.62)$ & 0.001 & 68.8 & $2.22(0.93-5.31)$ & 0.073 \\
\hline \multicolumn{8}{|l|}{ Adjuvant RT } \\
\hline No & 62 & 86.7 & 1.00 & & 80.6 & 1.00 & \\
\hline Yes & 82 & 80.9 & $0.64(0.26-1.60)$ & 0.344 & 85.2 & $1.38(0.62-3.09)$ & 0.425 \\
\hline \multicolumn{8}{|c|}{ Adjuvant chemotherapy } \\
\hline No & 122 & 88.3 & 1.00 & & 84.1 & 1.00 & \\
\hline Yes & 22 & 61.5 & $3.36(1.39-8.11)$ & 0.007 & 75.3 & $1.62(0.64-4.09)$ & 0.305 \\
\hline \multicolumn{8}{|c|}{ Stage (after surgery) } \\
\hline $0-\mathrm{I}$ & 48 & 97.9 & 1.00 & & 87.5 & 1.00 & \\
\hline II & 66 & 83.2 & $7.18(0.91-56.09)$ & 0.060 & 86.3 & $1.18(0.40-3.48)$ & 0.759 \\
\hline III & 27 & 59.2 & $20.29(2.60-58.52)$ & 0.004 & 71.1 & $2.68(0.89-8.06)$ & 0.080 \\
\hline
\end{tabular}




\section{Long-Term Outcome}

After a median follow-up of 49 months (range 3119 months), 4 (3\%) patients had a local relapse, 18 $(12.5 \%)$ had distant metastases, and 24 (17\%) died. Results of univariate analysis of factors associated with DFS and OS are shown in Table 3. In particular, HER-2-negative tumor $(p=0.08)$, grade G1 $(p<0.001)$, achievement of BCS $(p=0.001), \mathrm{Ki}-67 \leq 14 \% \quad(p=0.002)$, residual tumor $\leq 2 \mathrm{~cm}(p=0.007)$, number of metastatic nodes $\leq 3$ ( $p=0.001)$, administration of adjuvant chemotherapy $(p=0.007)$, and stage I disease after surgery $(p=0.004)$ were associated with a better DFS. Only BCS and grade G1 ( $p=0.001)$ were predictors of a better OS. Figure 1 refers to Kaplan-Meier analysis of DFS (Fig. 1a) and OS (Fig. 1b) according to type of surgery. At 5 years of follow-up, the estimated cumulative DFS rate was $88.6 \%$ for BCS and $57.5 \%$ for mastectomy, while the estimated cumulative OS rate was $86.1 \%$ for BCS and $65.8 \%$ for mastectomy.

At multivariate analyses, achievement of BCS $(p=0.009)$, tumor grade $\mathrm{G} 1(p=0.01)$, and a residual tumor size $\leq 2 \mathrm{~cm}$ after surgery ( $p=0.005)$ resulted as independent prognostic factors for DFS, while BCS and grade G1 maintained their significativity for OS ( $p=0.002$ and $p=0.005$, respectively) [Table 4].

\section{DISCUSSION}

This retrospective study was carried out in postmenopausal breast cancer patients who were candidates for mastectomy with the aim of evaluating the efficacy of NET with AIs in terms of clinical outcome and obtainment of breast conservation.

All women evaluated in the present study received NET with a third-generation $\mathrm{AI}$-letrozole, anastrozole, or exemestane. The three agents are considered equivalent in their antitumor activity and are supposed to have similar efficacy in both the neoadjuvant and adjuvant setting. ${ }^{23}$ BCS was performed in 121 (84\%) of 144 patients. This BCS rate is greater than that reported in clinical studies in which AIs had been administered as the primary treatment in patients with breast cancer. ${ }^{16,17,19}$ In particular, the P024 study $^{17}$ comparing letrozole versus tamoxifen, the IMPACT $^{19}$ and the PROACT ${ }^{16}$ trials, both comparing anastrozole versus tamoxifen, reported BCS rates of 45, 46, and $43 \%$, respectively, in the arm receiving AIs. The short duration of NET (only 3 months in the IMPACT and PROACT trials, and 4 months in the P024 study) is likely responsible for the low response rate observed in these studies. In another phase II study, the American College of Surgeons Oncology Group (ACOSOG) Z1031 trial, comparing response to the three AIs in the neoadjuvant setting,
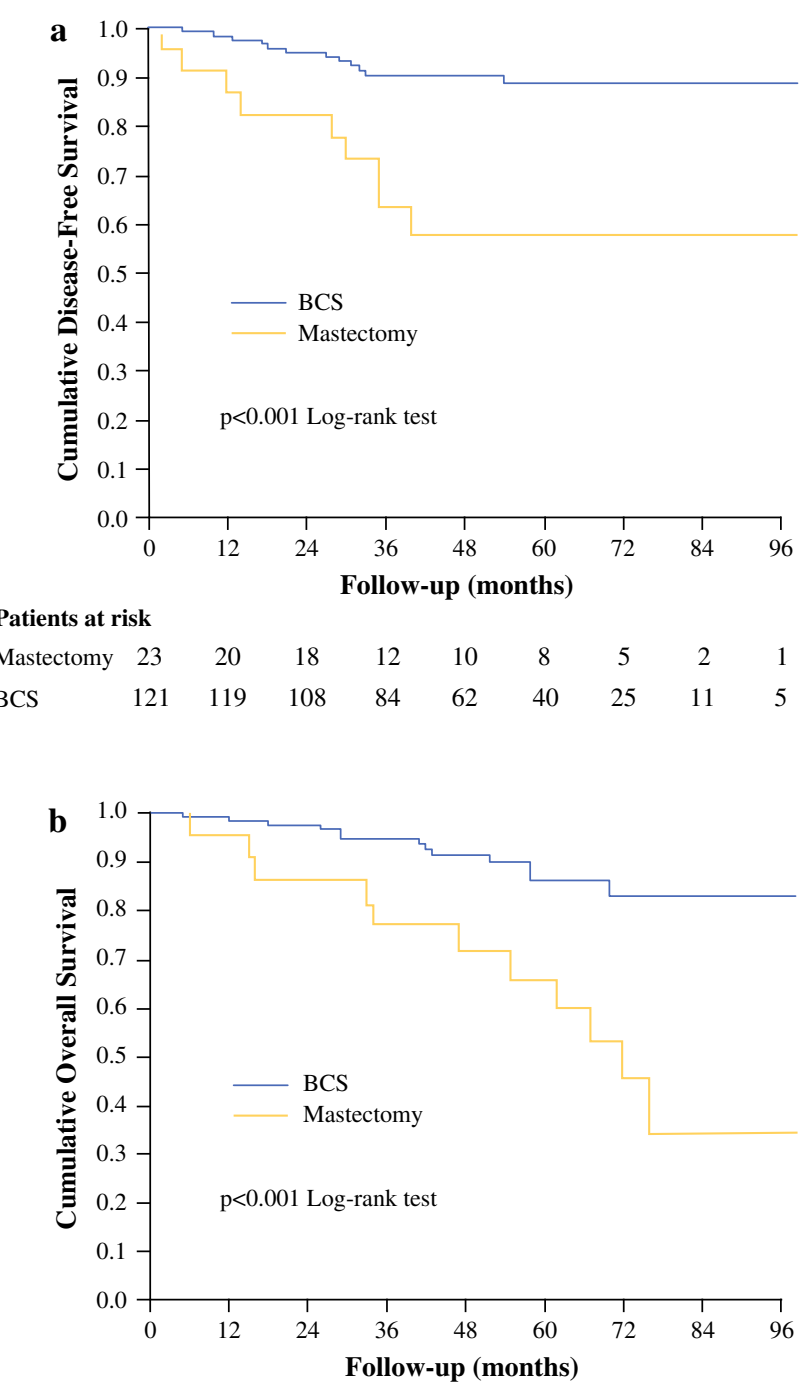

Patients at risk

$\begin{array}{llllllllll}\text { Mastectomy } & 23 & 21 & 19 & 16 & 13 & 11 & 7 & 3 & 2\end{array}$ $\begin{array}{llllllllll}\text { BCS } & 121 & 120 & 113 & 91 & 64 & 40 & 25 & 11 & 5\end{array}$

FIG. 1 Cumulative disease-free survival a and overall survival b stratified by type of surgery. $B C S$ breast conservative surgery

TABLE 4 Multivariate analysis of factors predictive of 5-year disease-free survival and overall survival

\begin{tabular}{lll}
\hline & HR $(95 \%$ CI $)$ & $p$ Value \\
\hline Disease-free survival & & \\
Grade (G2-G3 vs. G1) & $4.56(1.44-12.42)$ & $\mathbf{0 . 0 1 0}$ \\
Type of surgery (mastectomy & $8.11(1.68-19.08)$ & $\mathbf{0 . 0 0 9}$ \\
$\quad$ vs. BCS) & & \\
T stage (yT2-yT3 vs. yT0-yT1) & $7.92(1.88-13.43)$ & $\mathbf{0 . 0 0 5}$ \\
Overall survival & & \\
Grade (G2-G3 vs. G1) & $4.26(1.57-11.61)$ & $\mathbf{0 . 0 0 5}$ \\
Type of surgery (mastectomy & $8.86(2.29-7.47)$ & $\mathbf{0 . 0 0 2}$ \\
vs. BCS) & & \\
\hline
\end{tabular}

Bold values indicate significant $p$ values

$B C S$ breast conservative surgery 
the endocrine agents were administered for about 4 months and the overall BCS rate was $83.1 \%$ in the women considered 'marginal for BCS' at baseline, and around $50 \%$ in the women categorized as 'only eligible for mastectomy'. ${ }^{23}$ It is now generally accepted that the minimum duration of NET should be at least 4 months, but better results might be obtained with longer extension of time. ${ }^{24,25} \mathrm{~A}$ recent study comparing 4, 8, and 12 months of neoadjuvant letrozole showed that there was a time-dependent increase in overall response rate, which reflected in BCS rate ranging from 80 to $87.5 \% .{ }^{26}$ In our cohort, the duration of NET did not significantly influence the type of surgery, but the median time of AI administration was 6 months, with $85 \%$ of patients receiving NET for more than 5 months. Moreover, our series encompassed highly endocrine-responsive tumors (ER expression $\geq 60 \%$ ). This may contribute to the high rate of BCS we observed, since the probability of achieving a better response has been related to the level of expression of hormonal receptors. ${ }^{27}$ A trial on exemestane as NET set a cutoff $\geq 50 \%$ of ER-positive cells for patient eligibility. ${ }^{28}$ The above cited Z1031 trial $^{23}$ required ERpositive disease with high ER expression, i.e. Allred score of 6 to $8 .{ }^{29}$ It has been suggested that tumors with both ER and PR positivity in more than $50 \%$ of the cells might be considered highly endocrine responsive, while a positivity in less than $50 \%$ of the cells predicts an incomplete endocrine responsiveness. ${ }^{3}$ In our study, all patients had tumors with ER expression $\geq 60 \%$, and more than half $(63 \%)$ had both ER and PR $\geq 50 \%$.

The variables statistically associated with the achievement of BCS were tumor size $<3 \mathrm{~cm}$ at diagnosis and HER-2 negativity. The latter result probably reflects the intrinsic hormonal resistance of HER-2-positive tumors. ${ }^{30,31}$

BCS was performed in patients reporting clinical objective response (CR + PR) and was significantly associated with longer DFS and OS. Given that achievement of BCS strongly correlates with the clinical response of the primary tumor, the latter was not included as a variable in the multivariate analyses. We observed only two pCRs $(1.4 \%)$, in accordance with the low rate reported in NET studies, ranging from 1 to $10 \% .^{19,32-34} \mathrm{pCR}$, which is the most important prognostic factor for neoadjuvant chemotherapy, is not an appropriate surrogate marker for prognosis in patients with HR-positive tumors. In fact, patients with this subtype of breast cancer rarely obtain a pCR but have a good outcome, even in presence of residual disease. $^{3-8}$

Interestingly, our data indicate that grade G1 is a tumor biological characteristic strongly associated with longer DFS and OS. It has long been established that patients with well-differentiated breast cancer, including those with HRpositive tumor, have a better survival than those with G2 and G3 tumors. $^{35}$ However, in the last St. Gallen
Consensus Conference, ${ }^{24,36}$ the Ki-67 proliferation marker, ${ }^{37}$ rather than grading, was taken into consideration for the separation of HR-positive/HER-2-negative tumors in luminal A and luminal B subtypes, two groups with different prognosis. ${ }^{38}$ This recommendation was based on data suggesting that Ki-67 levels $>14 \%$ were able to identify a high-risk group in terms of prognosis. ${ }^{39,40}$ In the absence of Ki-67 determination, grading is still used to differentiate luminal molecular subtypes. ${ }^{8}$ The prognostic role of Ki-67 in breast cancer is controversial. Two different meta-analyses of studies on early breast cancer ${ }^{41,42}$ and a recent large retrospective study ${ }^{43}$ have shown that high levels of Ki-67 are associated with a worse prognosis. In addition, in HR-positive breast cancer, reduction of Ki67 after 2 weeks of NET correlated with better response and recurrence-free survival. ${ }^{44}$ On the contrary, another study conducted on patients with breast cancer receiving neoadjuvant chemotherapy showed no predictive or prognostic value of $\mathrm{Ki}-67$ in HR-positive/HER2-negative tumors. ${ }^{45}$ Given the great heterogeneity of patients in the different studies, and the different methods utilized to determine and score Ki-67, the American Society of Clinical Oncology (ASCO) Tumor Marker Guidelines Committee did not advise the routine use of Ki-67 for the estimation of prognosis in patients with breast cancer. ${ }^{46} \mathrm{In}$ our study, neither baseline expression of Ki-67 nor Ki-67 variations after NET influenced the long-term outcome (data not shown). It has been reported that the prognostic value of $\mathrm{Ki}-67$ is mainly attributed to the histological grade $\mathrm{G}^{2,47,48}$ and the prevalence of patients with G1 tumors $(67 \%)$ in our cohort may justify the lack of prognostic value of Ki-67. Another study evaluated the long-term outcome of patients after NET, showing that a low-risk profile (i.e. pT0/1, pN0, Ki6-67 $<2.7 \%$ and Allred score 3-8 for ER status, the so-called PEPI score) allowed to identify a group of patients with a very low risk of disease progression. ${ }^{49}$ Our data are in agreement with these results only for pathological stage, but not for Ki-67 and ER status, likely for the very high ER positivity and G1 tumor percentage in our patients' population, as emphasized above.

Finally, the high rate of BCS in our study is especially relevant considering that more than $90 \%$ of the patients were older than 65 years. In fact, in elderly patients most authors recommend a conservative surgery based on the increased risk of death from concomitant disease and the reduced risk of local recurrence. ${ }^{33,50,51}$ Moreover, the preservation of body image in older patients is an important psychological factor influencing both the quality of life and mental health. ${ }^{52-54}$

The limits of this retrospective study are mainly represented by single surgery team evaluation for patient eligibility to BCS prior to neoadjuvant therapy and the 
relatively small number of events to investigate long-term outcomes.

\section{CONCLUSIONS}

We show that elderly breast cancer patients with a tumor size $<3 \mathrm{~cm}$ at diagnosis and HER-2-negativity have a higher probability of achieving BCS after NET. Moreover, patients treated with BCS and with grade G1 tumor have a reduced risk of recurrence and death in the long-term follow-up. It is likely these patients are those who will benefit the most from preoperative endocrine therapy.

DISCLOSURES The authors declare that they have no conflict of interest.

Open Access This article is distributed under the terms of the Creative Commons Attribution License which permits any use, distribution, and reproduction in any medium, provided the original author(s) and the source are credited.

\section{REFERENCES}

1. Abrial C, Mouret-Reynier MA, Cure H, Feillel V, Leheurteur M, Lemery S, et al. Neoadjuvant endocrine therapy in breast cancer. Breast. 2006;15(1):9-19.

2. Kaufmann M, von Minckwitz G, Mamounas EP, Cameron D, Carey LA, Cristofanilli M, et al. Recommendations from an international consensus conference on the current status and future of neoadjuvant systemic therapy in primary breast cancer. Ann Surg Oncol. 2012;19(5):1508-16.

3. Colleoni M, Bagnardi V, Rotmensz N, Gelber RD, Viale G, Pruneri G, et al. Increasing steroid hormone receptors expression defines breast cancer subtypes non responsive to preoperative chemotherapy. Breast Cancer Res Treat. 2009;116(2):359-69.

4. Huober J, von Minckwitz G, Denkert C, Tesch H, Weiss E, Zahm $\mathrm{DM}$, et al. Effect of neoadjuvant anthracycline-taxane-based chemotherapy in different biological breast cancer phenotypes: overall results from the GeparTrio study. Breast Cancer Res Treat. 2010;124(1):133-40.

5. Kim SI, Sohn J, Koo JS, Park SH, Park HS, Park BW. Molecular subtypes and tumor response to neoadjuvant chemotherapy in patients with locally advanced breast cancer. Oncology. 2010;79(5-6):324-30.

6. Precht LM, Lowe KA, Atwood M, Beatty JD. Neoadjuvant chemotherapy of breast cancer: tumor markers as predictors of pathologic response, recurrence, and survival. Breast $J$. 2010;16(4):362-8.

7. Straver ME, Rutgers EJ, Rodenhuis S, Linn SC, Loo CE, Wesseling $\mathrm{J}$, et al. The relevance of breast cancer subtypes in the outcome of neoadjuvant chemotherapy. Ann Surg Oncol. 2010;17(9):2411-8.

8. von Minckwitz G, Untch M, Blohmer JU, Costa SD, Eidtmann H, Fasching PA, et al. Definition and impact of pathologic complete response on prognosis after neoadjuvant chemotherapy in various intrinsic breast cancer subtypes. J Clin Oncol. 2012;30(15):17961804.

9. Angelucci D, Tinari N, Grassadonia A, Cianchetti E, AusiliCefaro G, Iezzi L, et al. Long-term outcome of neoadjuvant systemic therapy for locally advanced breast cancer in routine clinical practice. J Cancer Res Clin Oncol. 2013;139(2):269-80.
10. Natoli C, Vici P, Sperduti I, Grassadonia A, Bisagni G, Tinari N, et al. Effectiveness of neoadjuvant trastuzumab and chemotherapy in HER2-overexpressing breast cancer. J Cancer Res Clin Oncol. 2013;139(7):1229-40.

11. Kaufmann M, Hortobagyi GN, Goldhirsch A, Scholl S, Makris A, Valagussa $\mathrm{P}$, et al. Recommendations from an international expert panel on the use of neoadjuvant (primary) systemic treatment of operable breast cancer: an update. J Clin Oncol. 2006;24(12):1940-9.

12. Kuerer HM, Newman LA, Smith TL, Ames FC, Hunt KK, Dhingra $\mathrm{K}$, et al. Clinical course of breast cancer patients with complete pathologic primary tumor and axillary lymph node response to doxorubicin-based neoadjuvant chemotherapy. J Clin Oncol. 1999;17(2):460-9.

13. Coates AS, Keshaviah A, Thurlimann B, Mouridsen H, Mauriac $\mathrm{L}$, Forbes JF, et al. Five years of letrozole compared with tamoxifen as initial adjuvant therapy for postmenopausal women with endocrine-responsive early breast cancer: update of study BIG 1-98. J Clin Oncol. 2007;25(5):486-92.

14. Coombes RC, Kilburn LS, Snowdon CF, Paridaens R, Coleman $\mathrm{RE}$, Jones SE, et al. Survival and safety of exemestane versus tamoxifen after 2-3 years' tamoxifen treatment (Intergroup Exemestane Study): a randomised controlled trial. Lancet. 2007;369(9561):559-70.

15. Forbes JF, Cuzick J, Buzdar A, Howell A, Tobias JS, Baum M. Effect of anastrozole and tamoxifen as adjuvant treatment for early-stage breast cancer: 100-month analysis of the ATAC trial. Lancet Oncol. 2008;9(1):45-53.

16. Cataliotti L, Buzdar AU, Noguchi S, Bines J, Takatsuka Y, Petrakova $\mathrm{K}$, et al. Comparison of anastrozole versus tamoxifen as preoperative therapy in postmenopausal women with hormone receptor-positive breast cancer: the Pre-Operative "Arimidex" Compared to Tamoxifen (PROACT) trial. Cancer. 2006;106(10): 2095-103.

17. Eiermann W, Paepke S, Appfelstaedt J, Llombart-Cussac A, Eremin J, Vinholes $\mathrm{J}$, et al. Preoperative treatment of postmenopausal breast cancer patients with letrozole: a randomized double-blind multicenter study. Ann Oncol. 2001;12(11):152732.

18. Seo JH, Kim YH, Kim JS. Meta-analysis of pre-operative aromatase inhibitor versus tamoxifen in postmenopausal woman with hormone receptor-positive breast cancer. Cancer Chemother Pharmacol. 2009;63(2):261-6.

19. Smith IE, Dowsett M, Ebbs SR, Dixon JM, Skene A, Blohmer $\mathrm{JU}$, et al. Neoadjuvant treatment of postmenopausal breast cancer with anastrozole, tamoxifen, or both in combination: the Immediate Preoperative Anastrozole, Tamoxifen, or Combined with Tamoxifen (IMPACT) multicenter double-blind randomized trial. $J$ Clin Oncol. 2005;23(22):5108-16.

20. Luu C, Goldstein L, Goldner B, Schoellhammer HF, Chen SL. Trends in radiotherapy after breast-conserving surgery in elderly patients with early-stage breast cancer. Ann Surg Oncol. 2013;20(10):3266-73.

21. Eisenhauer EA, Therasse P, Bogaerts J, Schwartz LH, Sargent D, Ford R, et al. New response evaluation criteria in solid tumours: revised RECIST guideline (version 1.1). Eur $J$ Cancer. 2009;45(2):228-47.

22. Deyarmin B, Kane JL, Valente AL, van Laar R, Gallagher C, Shriver CD, et al. Effect of ASCO/CAP guidelines for determining ER status on molecular subtype. Ann Surg Oncol. 2013;20(1):87-93.

23. Ellis MJ, Suman VJ, Hoog J, Lin L, Snider J, Prat A, et al. Randomized phase II neoadjuvant comparison between letrozole, anastrozole, and exemestane for postmenopausal women with estrogen receptor-rich stage 2 to 3 breast cancer: clinical and biomarker outcomes and predictive value of the baseline PAM50- 
based intrinsic subtype-ACOSOG Z1031. J Clin Oncol. 2011;29(17):2342-9.

24. Goldhirsch A, Wood WC, Coates AS, Gelber RD, Thurlimann B, Senn HJ. Strategies for subtypes-dealing with the diversity of breast cancer: highlights of the St. Gallen International Expert Consensus on the Primary Therapy of Early Breast Cancer 2011. Ann Oncol. 2011;22(8):1736-47.

25. Bottini A, Generali D, Brizzi MP, Fox SB, Bersiga A, Bonardi S, et al. Randomized phase II trial of letrozole and letrozole plus low-dose metronomic oral cyclophosphamide as primary systemic treatment in elderly breast cancer patients. J Clin Oncol. 2006;24(22):3623-8

26. Allevi G, Strina C, Andreis D, Zanoni V, Bazzola L, Bonardi S, et al. Increased pathological complete response rate after a longterm neoadjuvant letrozole treatment in postmenopausal oestrogen and/or progesterone receptor-positive breast cancer. $\mathrm{Br} \mathrm{J}$ Cancer. 2013;108(8):1587-92.

27. Ellis MJ, Coop A, Singh B, Mauriac L, Llombert-Cussac A, Jänicke $\mathrm{F}$, et al. Letrozole is more effective neoadjuvant endocrine therapy than tamoxifen for ErbB-1- and/or ErbB-2-positive, estrogen receptor-positive primary breast cancer: evidence from a phase III randomized trial. J Clin Oncol. 2001;19(18):3808-16.

28. Barnadas A, Gil M, Gonzalez S, Tusquets I, Muñoz M, Arcusa A, et al. Exemestane as primary treatment of oestrogen receptorpositive breast cancer in postmenopausal women: a phase II trial. Br J Cancer. 2009;100(3):442-9.

29. Allred DC, Harvey JM, Berardo M, Clark GM. Prognostic and predictive factors in breast cancer by immunohistochemical analysis. Mod Pathol. 1998;11(2):155-68.

30. Dowsett M, Allred C, Knox J, Quinn E, Salter J, Wale C, et al. Relationship between quantitative estrogen and progesterone receptor expression and human epidermal growth factor receptor 2 (HER2) status with recurrence in the Arimidex, Tamoxifen, Alone or in Combination Trial. J Clin Oncol. 2008;26(7):1059-65.

31. Rasmussen BB, Regan MM, Lykkesfeldt AE, Dell'Orto P, Del Curto B, Henriksen KL, et al. Adjuvant letrozole versus tamoxifen according to centrally-assessed ERBB2 status for postmenopausal women with endocrine-responsive early breast cancer: supplementary results from the BIG 1-98 randomised trial. Lancet Oncol. 2008;9(1):23-28.

32. Berruti A, Generali D, Kaufmann M, Puztai L, Curigliano G, Aglietta $\mathrm{M}$, et al. International expert consensus on primary systemic therapy in the management of early breast cancer: highlights of the Fourth Symposium on Primary Systemic Therapy in the Management of Operable Breast Cancer, Cremona, Italy (2010). J Natl Cancer Inst Monogr. 2011;2011(43):147-51.

33. Gruenberger T, Gorlitzer M, Soliman T, Rudas M, Mittlboeck M, Gnant $\mathrm{M}$, et al. It is possible to omit postoperative irradiation in a highly selected group of elderly breast cancer patients. Breast Cancer Res Treat. 1998;50(1):37-46.

34. Zambetti M, Mansutti M, Gomez P, Lluch A, Dittrich C, Zamagni $\mathrm{C}$, et al. Pathological complete response rates following different neoadjuvant chemotherapy regimens for operable breast cancer according to ER status, in two parallel, randomized phase II trials with an adaptive study design (ECTO II). Breast Cancer Res Treat. 2012;132(3):843-51.

35. Elston $\mathrm{CW}$, Ellis IO. Pathological prognostic factors in breast cancer: I. The value of histological grade in breast cancer: experience from a large study with long-term follow-up. Histopathology. 1991;19(5):403-10.

36. Curigliano G, Criscitiello C, Andre F, Colleoni M, Di Leo A. Highlights from the 13th St Gallen International Breast Cancer Conference 2013. Access to innovation for patients with breast cancer: how to speed it up? Ecancermedicalscience. 2013;7:299.
37. Urruticoechea A, Smith IE, Dowsett M. Proliferation marker Ki67 in early breast cancer. J Clin Oncol. 2005;23(28):7212-20.

38. Parker JS, Mullins M, Cheang MC, Leung S, Voduc D, Vickery $\mathrm{T}$, et al. Supervised risk predictor of breast cancer based on intrinsic subtypes. J Clin Oncol. 2009;27(8):1160-7.

39. Cheang MC, Chia SK, Voduc D, Gao D, Leung S, Snider J, et al. Ki67 index, HER2 status, and prognosis of patients with luminal B breast cancer. J Natl Cancer Inst. 2009;101(10):736-50.

40. Yerushalmi R, Woods R, Ravdin PM, Hayes MM, Gelmon KA. Ki67 in breast cancer: prognostic and predictive potential. Lancet Oncol. 2010;11(2):174-83.

41. de Azambuja E, Cardoso F, de Castro G Jr, Colozza M, Mano MS, Durbecq V, et al. Ki-67 as prognostic marker in early breast cancer: a meta-analysis of published studies involving 12,155 patients. Br J Cancer. 2007;96(10):1504-13.

42. Stuart-Harris R, Caldas C, Pinder SE, Pharoah P. Proliferation markers and survival in early breast cancer: a systematic review and metaanalysis of 85 studies in 32,825 patients. Breast. 2008;17(4):323-34.

43. Inwald EC, Klinkhammer-Schalke M, Hofstadter F, Zeman F, Koller M, Gerstenhauer M, et al. Ki-67 is a prognostic parameter in breast cancer patients: results of a large population-based cohort of a cancer registry. Breast Cancer Res Treat. 2013; 139(2):539-52.

44. Dowsett M, Smith IE, Ebbs SR, Dixon JM, Skene A, A'Hern R, et al. Prognostic value of Ki67 expression after short-term presurgical endocrine therapy for primary breast cancer. $J$ Natl Cancer Inst. 2007;99(2):167-70.

45. Lips EH, Mulder L, de Ronde JJ, Mandjes IA, Koolen BB, Wessels LF, et al. Breast cancer subtyping by immunohistochemistry and histological grade outperforms breast cancer intrinsic subtypes in predicting neoadjuvant chemotherapy response. Breast Cancer Res Treat. 2013;140(1):63-71.

46. Harris L, Fritsche H, Mennel R, Norton L, Ravdin P, Taube S, et al. American Society of Clinical Oncology 2007 update of recommendations for the use of tumor markers in breast cancer. $J$ Clin Oncol. Nov 20 2007;25(33):5287-312.

47. Aleskandarany MA, Rakha EA, Macmillan RD, Powe DG, Ellis IO, Green AR. MIB1/Ki-67 labelling index can classify grade 2 breast cancer into two clinically distinct subgroups. Breast Cancer Res Treat. 2011;127(3):591-9.

48. Klintman M, Bendahl PO, Grabau D, Lovgren K, Malmstrom P, Ferno M. The prognostic value of Ki67 is dependent on estrogen receptor status and histological grade in premenopausal patients with node-negative breast cancer. Mod Pathol. 2010;23(2):251-9.

49. Ellis MJ, Tao Y, Luo J, A’Hern R, Evans DB, Bhatnagar AS, et al. Outcome prediction for estrogen receptor-positive breast cancer based on postneoadjuvant endocrine therapy tumor characteristics. J Natl Cancer Inst. 2008;100(19):1380-8.

50. Nemoto T, Patel JK, Rosner D, Dao TL, Schuh M, Penetrante R. Factors affecting recurrence in lumpectomy without irradiation for breast cancer. Cancer. 1991;67(8):2079-82.

51. Veronesi U, Marubini E, Mariani L, Galimberti V, Luini A, Veronesi $\mathrm{P}$, et al. Radiotherapy after breast-conserving surgery in small breast carcinoma: long-term results of a randomized trial. Ann Oncol. 2001;12(7):997-1003.

52. Figueiredo MI, Cullen J, Hwang YT, Rowland JH, Mandelblatt JS. Breast cancer treatment in older women: does getting what you want improve your long-term body image and mental health? J Clin Oncol. 2004;22(19):4002-9.

53. Fentiman IS. Management of operable breast cancer in older women. J R Soc Med. 2013;106(1):13-18.

54. In H, Jiang W, Lipsitz SR, Neville BA, Weeks JC, Greenberg CC. Variation in the utilization of reconstruction following mastectomy in elderly women. Ann Surg Oncol. 2013;20(6):1872-9. 